\title{
An explanation for another familial case of Rett syndrome: maternal germline mosaicism
}

\author{
Margarida Venâncio ${ }^{1}$, Mónica Santos ${ }^{2}$, Susana Aires Pereira ${ }^{3}$, Patrícia Maciel ${ }^{2}$ and \\ Jorge M Saraiva*,1
}

\begin{abstract}
${ }^{1}$ Serviço de Genética Médica, Hospital Pediátrico de Coimbra, Coimbra, Portugal; ${ }^{2}$ Instituto de Ciências da Vida e da Saúde (ICVS), Escola das Ciências da Saúde, Universidade do Minho, Braga, Portugal; ${ }^{3}$ Serviço de Pediatria, Centro Hospitalar de Vila Nova de Gaia, Portugal
\end{abstract}

Rett syndrome (RTT; OMIM\#312750) is a severe neurodevelopmental disorder that affects mainly girls. It has an estimated incidence of 1:10000-15000 females. Mutations in the X-linked gene methyl CpGbinding protein 2 (MECP2) have been found in most patients. The most accepted explanation for the sex bias is that the Rett mutation in sporadic cases has its origin in the paternal germline $\mathrm{X}$ chromosome and can thus only be transmitted to females. The majority of cases are sporadic (99.5\%) but some familial cases have been described. These cases can either be explained by germline mosaicism or by asymptomatic carrier mothers with skewing of X-inactivation towards the wild-type MECP2 allele. We describe one of the few familial cases of RTT in which a maternal germline mosaicism is the most likely explanation. The mutation p.Arg270fs (c.808delC) was identified in both a girl with classical RTT and her brother who had the severe neurological phenotype usually described in males. The mutation was absent in DNA extracted from blood of both parents. These type of events must be taken into consideration in the genetic counselling of families after the diagnosis of a first case of RTT in a female or a MECP2 mutation in a male. European Journal of Human Genetics (2007) 15, 902-904; doi:10.1038/sj.ejhg.5201835; published online 18 April 2007

Keywords: Rett syndrome; maternal germline mosaicism; MECP2

\section{Introduction}

Rett syndrome (RTT; OMIM\#312750) is a severe neurodevelopmental disorder that affects mainly girls. ${ }^{1}$ It has an estimated incidence of 1:10000-15000 females $^{2}$ and is one of the leading causes of mental retardation in this sex. ${ }^{3}$ The diagnosis is based on the established criteria defined by Hagberg. ${ }^{4}$ Mutations in the X-linked gene methyl CpG-binding protein 2 (MECP2) have been found in most patients. ${ }^{5}$ Recently other genes $\left(C D K L 5^{6}\right.$ and Netrin $\left.G 1^{7}\right)$ have been linked to this disease. Male lethality and uniparental disomy have been proposed as possible

\footnotetext{
*Correspondence: Professor JM Saraiva, Serviço de Genética Médica, Hospital Pediátrico de Coimbra, Av Bissaya Barreto, 3000-075 Coimbra, Portugal. Tel: + 351239480 638; Fax: + 351239717 216; E-mail: j.saraiva@hpc.chc.min-saude.pt Received 29 September 2006; revised 8 March 2007; accepted 17 March 2007; published online 18 April 2007
}

explanations for the sex bias. The most interesting suggestion, proposed by several authors ${ }^{8,9}$ is that the Rett mutation in sporadic cases has its origin in the paternal germline $\mathrm{X}$ chromosome and can thus only be transmitted to females. The majority of cases are sporadic $(99.5 \%) .{ }^{10}$ Only a few familial cases with documented MECP2 mutation have been reported. Some were explained by skewing of $\mathrm{X}$-inactivation towards the wild type allele of MECP2 in an asymptomatic carrier. In others, five, germline mosaicism (four maternal ${ }^{2,8,11,12}$ and one paternal ${ }^{13}$ ) was a possible explanation.

\footnotetext{
Clinical description

Case 1

The index case is a 3-year-old girl who was referred to us due to moderate developmental delay, severe growth
} 
retardation (weight, $11.010 \mathrm{~kg}(<\mathrm{P} 5)$, standing height, $85 \mathrm{~cm}(<\mathrm{P} 5)$, head circumference, $46 \mathrm{~cm}(<\mathrm{P} 5))$ since birth, and desacceleration of the head growth, ataxic gait, and hand stereotypies since 24 months of age. The prenatal and perinatal history was considered normal. A thorough investigation (for chromosomal, neurological and metabolic disorders) had already been performed without any diagnostic results. In our observation, non-relevant dysmorphisms were noted, and the diagnoses of RTT and Angelman syndrome (AS) were considered. The molecular study for the AS revealed a biparental pattern of methylation. The molecular analysis of MECP2 gene detected the mutation p.Arg270fs (c.808delC) (described in the RettBASE: IRSA MECP2 Variation Database, http://mecp2. chw.edu.au/mecp2/), thus confirming the diagnosis of RTT.

\section{Case 2}

Her younger brother was 1-year-old when the diagnosis of RTT was carried out after being confirmed on his sister. The same mutation was found on the MECP2 gene. His prenatal history was considered normal, but since early age severe growth retardation and development delay was noted. At birth, his somatometric parameters were within the normal range for a 38 weeks' gestation (weight, $2330 \mathrm{~g}$ (P3), recumbent height, $44 \mathrm{~cm}$ ( $\mathrm{P} 3-10)$, head circumference, $32.3 \mathrm{~cm}(\mathrm{P} 10-25))$ as well as his Apgar score (7 at the first minute and 9 at the fifth minute). However, due to food refusal, he was admitted in a neonatal intensive care unit for a week. When he was 8 months old, his somatometric evaluation was consistent with severe growth retardation (weight, $5150 \mathrm{~g}(<\mathrm{P} 5)$, recumbent height, $60.1 \mathrm{~cm}(<\mathrm{P} 5)$, head circumference, $38.3 \mathrm{~cm}(<\mathrm{P} 5))$. He was hypotonic and had very poor visual contact and facial mimic, weak crying and repetitive oral facial and lingual movements. He showed synophris, upslanting palpebral fissures and micrognathia. His cytogenetic study was normal $(46, X Y)$. An electroencephalogram was also performed; it revealed low paroxistical activity at the right temporal region.

The developmental assessment, at 17 months of age, using the Ruth Griffiths Mental Development Scales confirmed the severe developmental delay. The overall developmental quotient was extremely difficult to evaluate (5\%). He had a mental age corresponding to 1 month and his functional level was below 3 months. The speech and hearing and eye-hand tests coordination presented the worse scores (3\%). The performance, locomotor and personal-social subscales showed a value of $6 \%$. The locomotor evaluation showed that when on ventral position he could only push our hands with his feet but not raise his head and upper body. On ventral prone, he merely tried to rotate the head and was not able to raise it or to pull himself into a crawl position. He could not sit without support but held the head erect and the back straightened for only very short periods of time. The personal-social development revealed that he sporadically smiled responsively and liked having bath. He felt secure when he was held but did not try to reach the person. Regarding the hearing and language area, his skills were very poor (he reacted badly to loud sounds; did not turn his head towards a sound source; and could simply make some vocalizations). On the hand and eye coordination testing, he sometimes followed a light horizontally, but did not stare at or follow an object. He could not change his look between two objects or tried to grab it in the midline. The performance analysis showed that he reacted to paper when it was in front of him but did not try to reach it. His hands were more or less open and he put them sometimes on the mouth but he was not able to hold a cube on his hand.

He died at 21 months of age due to severe metabolic disequilibrium during a gastrointestinal infectious disease.

The molecular analysis of MECP2 gene of their parents peripheral blood revealed that neither of them was a carrier for that mutation.

\section{Conclusion}

We describe one of the few familial cases of RTT, in which a maternal germline mosaicism is the most likely explanation. We have described two children of a non-carrier couple, a girl with a classical form of RTT and a boy with a more severe and atypical presentation.

As reviewed previously in a paper by Williamson et al, ${ }^{5}$ most RTT patients are sporadic and the recurrence risk is low. However, maternal heterozygoty with X-inactivation is a possibility that can be excluded by molecular studies. Even then maternal gonadal mosaicism may exist as once again described in this family.

The presence of the same mutation in a male sib has a recognized phenotype difference. However, our patient has a milder disease than expected. This should be taken into account regarding the indication for MECP2 molecular studies in males.

Being the proband male, the probability of a maternal heterozygosity or germline mosaicism is greater and the parents should be made aware of this fact.

The knowledge of the rare events described here will be useful regarding the genetic counselling of families where a first diagnosis of RTT in a female or MECP2 mutation in a male is carried out. ${ }^{10,12}$

\section{References}

1 Weaving LS, Ellaway CJ, Gecz J, Christodoulou J: Rett syndrome: clinical review and genetic update. J Med Genet 2005; 42: 1-7.

2 Wan M, Lee SS, Zhang $\mathrm{X}$ et al: Rett syndrome and beyond: recurrent spontaneous and familial MECP2 mutations at CpG hotspots. Am J Hum Genet 1999; 65: 1520-1529.

3 Gill H, Cheadle JP, Maynard J et al: Mutation analysis in the MECP2 gene and genetic counselling for Rett syndrome. J Med Genet 2003; 40: 380-384. 
4 Hagberg B, Hanefeld F, Percy A, Skjeldal O: An update on clinically applicable diagnostic criteria in Rett syndrome. Comments to Rett Syndrome Clinical Criteria Consensus Panel Satellite to European Paediatric Neurology Society Meeting, Baden Baden, Germany, 11 September 2001. Eur J Paediatr Neurol 2002; 6: 293-297.

5 Williamson SL, Christodoulou J: Rett syndrome: new clinical and molecular insights. Eur J Hum Genet 2006; 14: 896-903.

6 Weaving LS, Christodoulou J, Williamson SL et al: Mutations of CDKL5 cause a severe neurodevelopmental disorder with infantile spasms and mental retardation. Am J Hum Genet 2004; 75: 1079-1093.

7 Borg I, Freude K, Kubart S et al: Disruption of Netrin G1 by a balanced chromosome translocation in a girl with Rett syndrome. Eur J Hum Genet 2005; 13: 921-927.

8 Villard L, Levy N, Xiang F et al: Segregation of a totally skewed pattern of $\mathrm{X}$ chromosome inactivation in four familial cases of Rett syndrome without MECP2 mutation: implications for the disease. J Med Genet 2001; 38: 435-442.
9 Trappe R, Laccone F, Cobilanschi J et al: MECP2 mutations in sporadic cases of Rett syndrome are almost exclusively of paternal origin. Am J Hum Genet 2001; 68: 1093-1101.

10 Mari F, Caselli R, Russo S et al: Germline mosaicism in Rett syndrome identified by prenatal diagnosis. Clin Genet 2005; 67: 258-260.

11 Amir RE, Van den Veyver IB, Wan M, Tran CQ, Francke U, Zoghbi HY: Rett syndrome is caused by mutations in X-linked MECP2, encoding methyl-CpG-binding protein 2. Nat Genet 1999; 23: 185-188.

12 Yaron Y, Ben Zeev B, Shomrat R, Bercovich D, Naiman T, OrrUrtreger A: MECP2 mutations in Israel: implications for molecular analysis, genetic counseling, and prenatal diagnosis in Rett syndrome. Hum Mutat 2002; 20: 323-324.

13 Evans JC, Archer HL, Whatley SD, Clarke A: Germline mosaicism for a MECP2 mutation in a man with two Rett daughters. Clin Genet 2006; 70: 336-338. 